\title{
Evaluation of the efficiency of systems to reduce vibration on modern tracklaying tractors
}

\author{
Domenico Pessina, Davide Facchinetti, Valentina Bonalume \\ Department of Agricultural Engineering, University of Milano, Italy
}

\begin{abstract}
Agricultural operators run a very high risk of exposure to mechanical vibration. To improve comfort, many different devices have recently been fitted to agricultural self-propelled machinery, especially on the most modern high-powered wheeled tractors. In contrast, agricultural tracklaying tractors are not equipped with a suspended cab floor and frequently poor or no seat suspension is fitted. Consequently, the levels of vibration measured in the driving seat of tracklaying tractors often widely exceed the limit stipulated by official national standards. The manufacturers of tracklaying tractors are currently trying to improve the level of comfort at the driver's place by reducing both the production and the transmission of vibration. The vibration levels at the driving seat of a group of tracklaying tractors produced by some leading Italian manufacturers were so measured. The models examined in the study differed in having either 5- or 6-roller track support, different types and stiffness of seat suspension, and in whether or not they were coupled to an implement. The type of seat suspension, and above all its correct adjustment, dramatically influenced the level of vibration, as did the increase in the number of track rollers. In contrast, whether or not the tractor was coupled to an implement at the rear 3-point linkage did not make any significant change to the vibration comfort during transport. Also on the best modern trackalying tractor models, vibration levels frequently exceed stipulated limits, so that a further reduction is urgently required. Possible solutions that could be developed may involve the universal adoption of rubber tracks and/or the fitting of silent blocks on the cab floor and suspension devices on one or both axles.
\end{abstract}

Correspondence: Domenico Pessina, Department of Agricultural Engineering, University of Milano, via Celoria, 2 - 20133 Milan, Italy. Tel. +39.02.503.16876 - Fax +39.02.503.16845.

E-mail: domenico.pessina@unimi.it

Key words: comfort, seat suspension, track rollers.

Contributions: all authors contributed equally to this paper.

Received for publication: 11 February 2012.

Accepted for publication: 13 April 2012.

(C) Copyright D. Pessina et al., 2012

Licensee PAGEPress, Italy

Journal of Agricultural Engineering 2012; XLIII:e7

doi:10.4081/jae.2012.e7

This article is distributed under the terms of the Creative Commons Attribution Noncommercial License (by-nc 3.0) which permits any noncommercial use, distribution, and reproduction in any medium, provided the original author(s) and source are credited.

\section{Introduction}

In the agricultural sector, working conditions are frequently poor and drivers of agricultural self-propelled machinery are still at risk of high levels of vibration exposure (Scarlett et al., 2007). The European Union Directive No. 2002/44/CE (European Commission, 2002) defines the criteria for measuring and then calculating the level of vibration. National guidelines have been formulated to reduce the risk and are reported in the Italian Decree No. 81/2008. In order to define minimum health and safety requirements in the work place, the Decree also specifies the most suitable national standard to be adopted. The working conditions and the manufacturing characteristics of the machinery can have a big impact on vibration levels such as the travelling speed and the soil surface profile (Servadio et al., 2007). These include the travelling speed and the soil surface profile. In fact, very high acceleration values are normally recorded when carrying out agricultural operations at high speed along hard and irregular surfaces (Solecki, 2007). On modern agricultural tractors, many devices have recently been fitted to improve vibration comfort. Apart from the driver's seat, equipped with a passive or sometimes with an active electronically controlled pneumatic suspension, pneumatic or hydraulic suspensions on the cab floor and the front axle have recently been fitted. A more elastic tyre wall combined with a low inflation pressure can improve operator comfort, especially on hard surfaces at high speed (Pessina, 1993). The type of seat suspension, and above all its correct adjustment (related to the driver's mass), also have a big impact on the level of vibration (Nuccitelli et al., 1993). Furthermore, the ride comfort is also very sensitive to the stiffness of the rear suspension of the cab (Uys et al., 2007): the hydropneumatic suspension can significantly improve the situation (Hammes and Meyer, 2010). In particular, the active or semi-active cab suspension is able to reduce the level of vibration with respect to traditional types (Deprez et al., 2005).

Nevertheless, all these have only been applied on the latest wheeled tractors, especially on high-powered models. Unfortunately, conditions of agricultural tracklaying tractors are still very poor: at the moment, no cab or front axle suspension systems are provided, even on recent models. As a consequence, the vibration levels measured often widely exceed the limits provided by the official national standards.

The manufacturers of tracklaying tractors are currently working on trying to improve the level of operator comfort, and are attempting to reduce both the production and the transmission of the vibration. Attention is being paid to both the low and high frequency parts of the spectrum. In the first case, the vibration is produced by the tractor traveling on hard or compacted surfaces and the seat suspension is designed to reduce its transmission. In the second, the vibration is generated by the running engine and gearbox; silent blocks fitted between the tractor body and the floor reduce their propagation. Also, some tractor parameters can influence the vibration level in the driving seat: the wheelbase and the distribution of mass in the cab, among others, play an important role. 


\section{Materials and methods}

The Whole Body Vibration (WBV) in the driving seat of a group of tracklaying tractors produced by some leading Italian manufacturers with different technical characteristics were measured, recorded and compared. Three medium powered tracklaying tractors equipped with steel tracks were considered (A, B and C), each produced by a different Italian manufacturer. Their main technical characteristics are summarized in Table 1; all tractors were equipped with a seat with a mechanical suspension.

Given that very high vibration levels were recorded in the driving seat, a $4^{\text {th }}$ tractor model (D, very similar to A) was tested in two versions arranged on different machines. In order to evaluate the level of vibration of a theoretically more stable and comfortable tracklaying machine, the traditional $\mathrm{D}(1)$ arrangement was compared with the $D(2)$ version that was equipped with a seat with a pneumatic suspension and, above all, a 6 -roller track instead of the conventional 5-roller version (Figure 1). The addition of one roller in the track system leads to an increase of $200 \mathrm{~mm}$ of the wheelbase: from 1650 to $1850 \mathrm{~mm}$.

Furthermore, to evaluate the influence of a correct (or incorrect) seat suspension setting, all the tests (carried out in three runs for each testing condition) were repeated, adjusting the suspension to the most stiff (equivalent to an operator mass of $130 \mathrm{~kg}$ ), the correct $(90 \mathrm{~kg})$ and the most soft $(50 \mathrm{~kg})$ settings (Table 2).

Two paths, each approximately $200 \mathrm{~m}$ long, were selected on a sloping farm track of compacted clay soil. These were run separately (the first uphill and the second downhill) at approximately $1 \mathrm{~min}$ each at a speed of $7 \mathrm{~km} / \mathrm{h}$. The three tractors A, B and C, were tested uncoupled. In order to simulate daily working conditions, the two tractors D1 and D2 were coupled with a ripper (working width 1.80 $\mathrm{m}$, typical working depth $0.60 \mathrm{~m}$, mass $480 \mathrm{~kg}$ ) hitched to the 3 -point linkage. WBV values were measured on the driver's seat, using a triaxial accelerometer Dytran 5313M2 (mass 11 g, sensitivity 99.3 $\mathrm{mV} / \mathrm{g}$ ) operated by a 4-channel human vibration meter (Quest Technologies HAVPro) complying with ISO 8041:1990 standards. Data elaboration took into consideration the provisions of the
European Union Directive No. 2002/44/EC (European Commission, 2002) concerning:

$$
\mathrm{a}_{\mathrm{wmax}}=\max \left(1.4 \mathrm{a}_{\mathrm{wx}} ; 1.4 \mathrm{a}_{\mathrm{wy}} ; \mathrm{a}_{\mathrm{wz}}\right)
$$

As an alternative, the ISO 2631-1:1997 standard was considered, as follows:

- single axes values: $\mathrm{a}_{\mathrm{wx}} ; \mathrm{a}_{\mathrm{wy}} ; \mathrm{a}_{\mathrm{wz}}$

- overall root mean square (RMS) value:

$$
\left.\mathrm{a}_{\mathrm{wsum}}=\left[\left(1.4 \mathrm{a}_{\mathrm{wx}}\right)^{2}+\left(1.4 \mathrm{a}_{\mathrm{wy}}\right)^{2}+\mathrm{a}_{\mathrm{wz}}{ }^{2}\right)\right]^{1 / 2}
$$

The Italian Decree No. 81/2008 currently in force concerning evaluation of vibration (referred to in the previous Italian Decree No. 187/2005 and subsequent European Community Directive No. 2002/44/CE), provides for the comparison of the limits with the awmax values obtained. However, the present study considered the single axes (in terms of $1.4 \mathrm{a}_{\mathrm{wx}} ; 1.4 \mathrm{a}_{\mathrm{wy}} ; \mathrm{a}_{\mathrm{wz}}$ ) and the awsum values because they seem to better represent the real disturbance to the driver caused by vibrations.

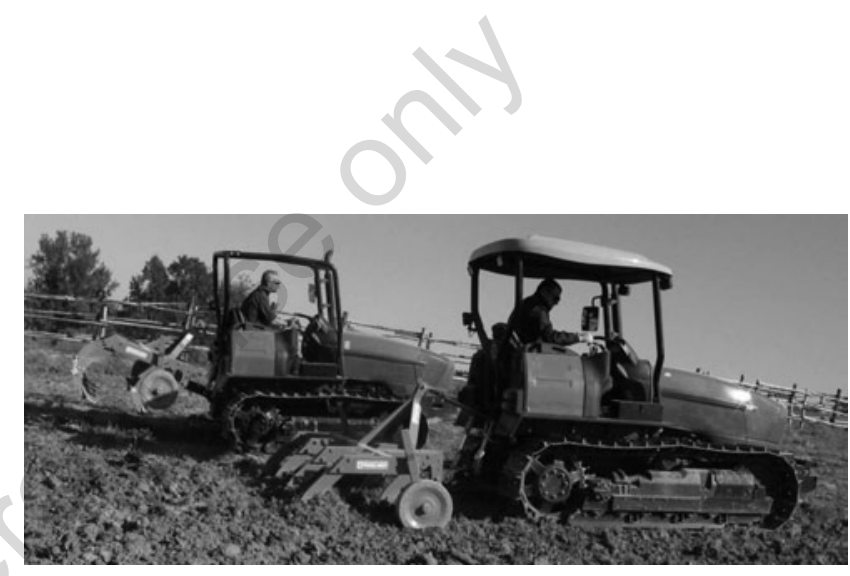

Figure 1. Tractor D in version D1 (left) equipped with a 5-roller track support and seat with mechanical suspension, and in version D2 (right) with a 6-roller track support and seat with pneumatic suspension.

\begin{tabular}{|c|c|c|c|c|c|c|}
\hline Tested tractor & Seat suspension type & $\begin{array}{l}\text { Seat suspension } \\
\text { stiffness }\end{array}$ & $\begin{array}{l}\text { Engine max. power, } \\
\text { kW }\end{array}$ & $\begin{array}{l}\text { Mass. } \\
\text { kg }\end{array}$ & $\begin{array}{c}\text { Wheelbase, } \\
\text { mm }\end{array}$ & $\begin{array}{l}\text { Track width, } \\
\text { mm }\end{array}$ \\
\hline $\mathrm{A}$ & Mechanical & Max. stiff, correct, max. soft & 75.3 & 5470 & 1650 & 1350 \\
\hline B & Mechanical & Max. stiff, correct, max. soft & 74.5 & 4900 & 1656 & 1300 \\
\hline $\mathrm{C}$ & Mechanical & Max. stiff, correct, max. soft & 72.5 & 4690 & 1650 & 1300 \\
\hline
\end{tabular}

Table 1. Main technical characteristics and settings of the 3 tested tracklaying tractors produced by different Italian manufacturers.

Table 2. Settings of the tested tractor $\mathrm{D}$, in version $\mathrm{D}(1)$ with 5-roller track support and mechanical seat suspension, and version $\mathrm{D}(2)$ with 6-roller track support and pneumatic suspension.

\begin{tabular}{lcccccc} 
Tested tractor & $\begin{array}{c}\text { Track support } \\
\text { rollers no. }\end{array}$ & $\begin{array}{c}\text { Seat suspension } \\
\text { type }\end{array}$ & $\begin{array}{c}\text { Seat suspension } \\
\text { setting }\end{array}$ & $\begin{array}{c}\text { Mass, } \\
\text { kg }\end{array}$ & $\begin{array}{c}\text { Wheelbase, } \\
\text { mm }\end{array}$ & $\begin{array}{c}\text { Track width, } \\
\text { mm }\end{array}$ \\
D1 & 5 & Mechanical & Max stiff, correct, max soft & 5470 & 1650 & 1350 \\
D2 & 6 & Pneumatic & Max stiff, correct, max soft & 5620 & 1850 & 1350 \\
\hline
\end{tabular}




\section{Results and discussion}

Results recorded on the three comparable traditional tractors are shown in Figure 2. For clarity, only the $\mathrm{z}$ (vertical) axis values have been reported, as this is the direction that offers the most effective damping action of the seat suspension device. Furthermore, the vibration in the vertical direction is the most dangerous for the drivers because it affects the vertebral column and, in particular, the intervertebral elasticity of the discs. In general, levels are quite high, exceeding $0.5 \mathrm{~m} / \mathrm{s}^{2}$ in $94 \%$ and $1.0 \mathrm{~m} / \mathrm{s}^{2}$ in $66 \%$ of the cases examined. This confirms the seriousness of the situation considering that the real $\mathrm{a}_{\text {wsum }}$ levels are even higher due to the contribution of the vibration in the two other horizontal axes, $\mathrm{x}$ (longitudinal) and $\mathrm{y}$ (transversal). Tractors A and B showed similar levels, but vehicle $\mathrm{C}$ was the least comfortable showing remarkable differences in comparison with the others in all the test conditions.

The seat suspension setting dramatically influenced levels: both the most soft and stiff settings revealed quite a high vibration increase in tractors A and B. As expected, the worst results were recorded with the highest stiffness, but surprisingly also the softest showed a poor comfort level. In this last case, the vibration increase was probably due to the frequent peaks recorded when the suspension spring reaches its maximum displacement in compression and, therefore, its damping action is completely interrupted.

The fact that there was reduced comfort with an incorrect seat setting is quite remarkable, reaching an increase that ranges from approximately $90 \%$ and $270 \%$. This confirms the importance of a correct adjustment in order to assure the best suspension performance.

Tractor C highlighted a poor general comfort level and small differences among the different suspension adjustments; the highest values were measured at the most soft setting. However, the increase in suspension stiffness did not cause any significant worsening of the damping quality, also when compared with the correct setting.

No great difference was observed between the two paths considered for the tests (uphill and downhill on a sloped farm track of compacted clay soil). In spite of the constant traveling speed, the uphill path was less smooth than the downhill because the levels measured were always higher. This first set of results were alarming and suggested the need for a new series of measurements to be taken in order to identify the improvements that could be made. The first modification was to change the driver's seat. A model equipped with a pneumatic rather than a mechanical suspension was so fitted. In fact, it is widely recognized that the pneumatic spring provides superior damping. Second, the fitting of a 6-roller track, instead of the traditional type with 5 rollers, introduced two potential benefits: a) an increase in the wheelbase $(+12 \%)$ and, consequently, an improvement in the longitudinal stability of the tractor; b) an increase in the total track area in contact with the ground which is better able to absorb the unevenness of the soil when traveling. Figures 3 and 4 show the weighted vibration levels recorded according to the two paths: uphill (rougher) and downhill (smoother).

The correct adjustment of the stiffness of the suspension provided better results in the $\mathrm{z}$ (vertical) axis, especially travelling uphill; the two other horizontal directions of vibration performed better, considering the downhill path, for the mechanical seat. This was probably due to the involuntary compensatory movements of the driver's body, trying to maintain the best equilibrium when encountering an uneven surface. No great difference was seen between the levels recorded in the three axes of the seat with pneumatic suspension (combined with the 6 -roller track fitting). Values were always lower (in some cases remarkably lower) than those recorded on the mechanical seat and 5-roller track combination, both traveling uphill and downhill. This is quite a good result, considering also that, on adopting the most favorable

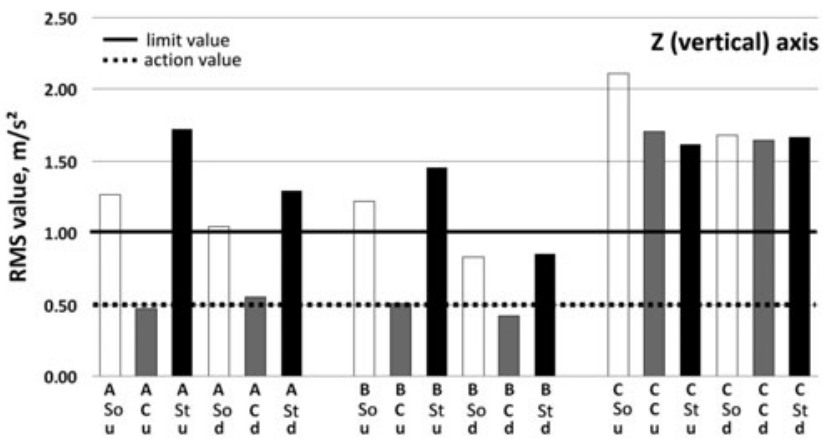

\section{Key}

$A, B, C=$ tracklaying tractors tested

So, C, St = max Soft, Correct, max Stiff seat suspension adjustment

$u, d=$ uphill, downhill traveling path

Figure 2. Weighted vibration levels measured on $\mathrm{z}$ axis (awz) on conventional tractors $\mathrm{A}, \mathrm{B}$ and $\mathrm{C}$, tested with different seat suspension adjustments, traveling uphill and downhill. A theoretical comparison with values stipulated by the Italian Decree No. $81 / 2008$ is shown. Exposure action value, $0.5 \mathrm{~m} / \mathrm{s}^{2}$; exposure limit value, $1.0 \mathrm{~m} / \mathrm{s}^{2}$. RMS, root mean square.

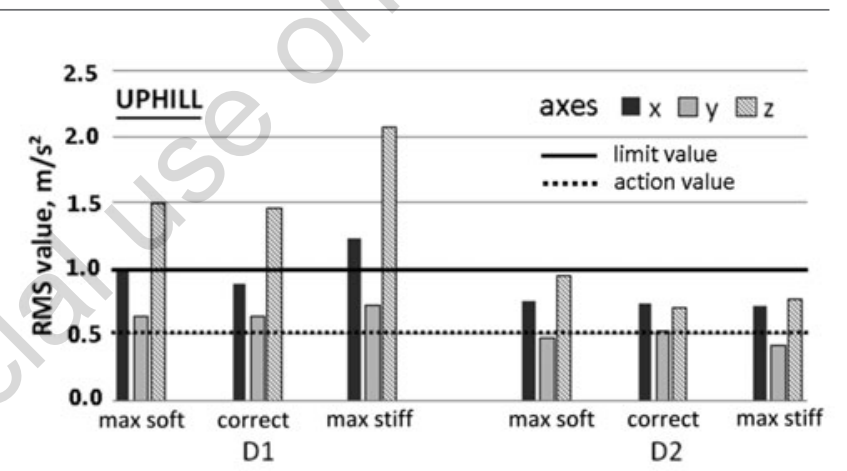

Key

$\overline{\mathrm{D} 1}=$ mechanical seat susp.; 5 -roller tracks

$\mathrm{D} 2$ = pneumatic seat susp.; 6 -roller tracks

Figure 3. Weighted vibration levels measured on tractors D1 and D2, travelling uphill. A theoretical comparison with values stipulated by the Italian Decree No. 81/2008 is shown. Exposure action value, $0.5 \mathrm{~m} / \mathrm{s}^{2}$; exposure limit value, $1.0 \mathrm{~m} / \mathrm{s}^{2}$. RMS, root mean square.

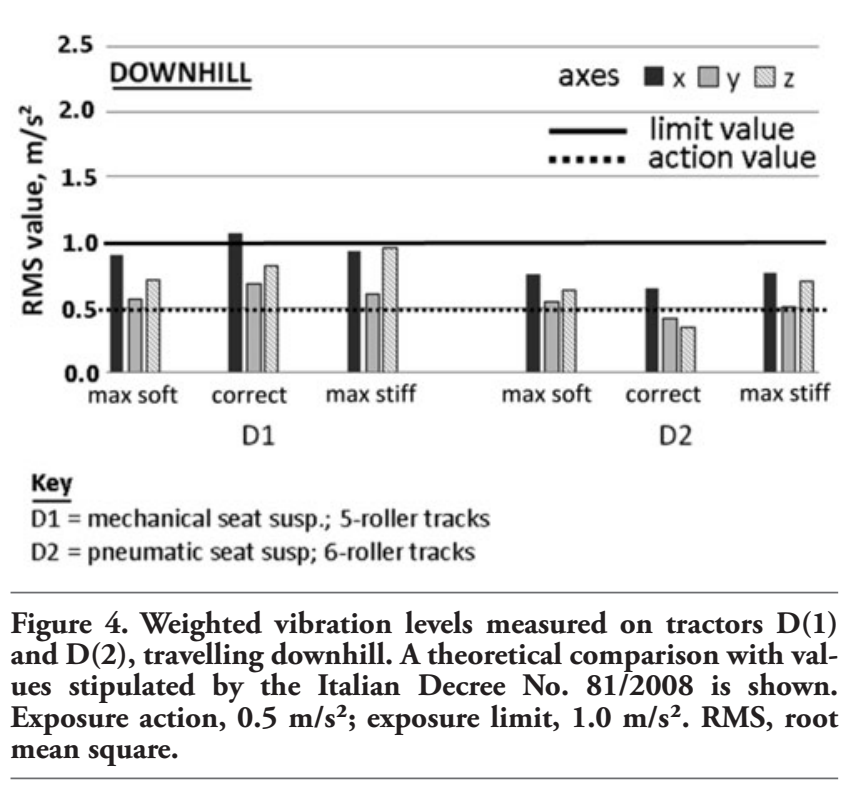



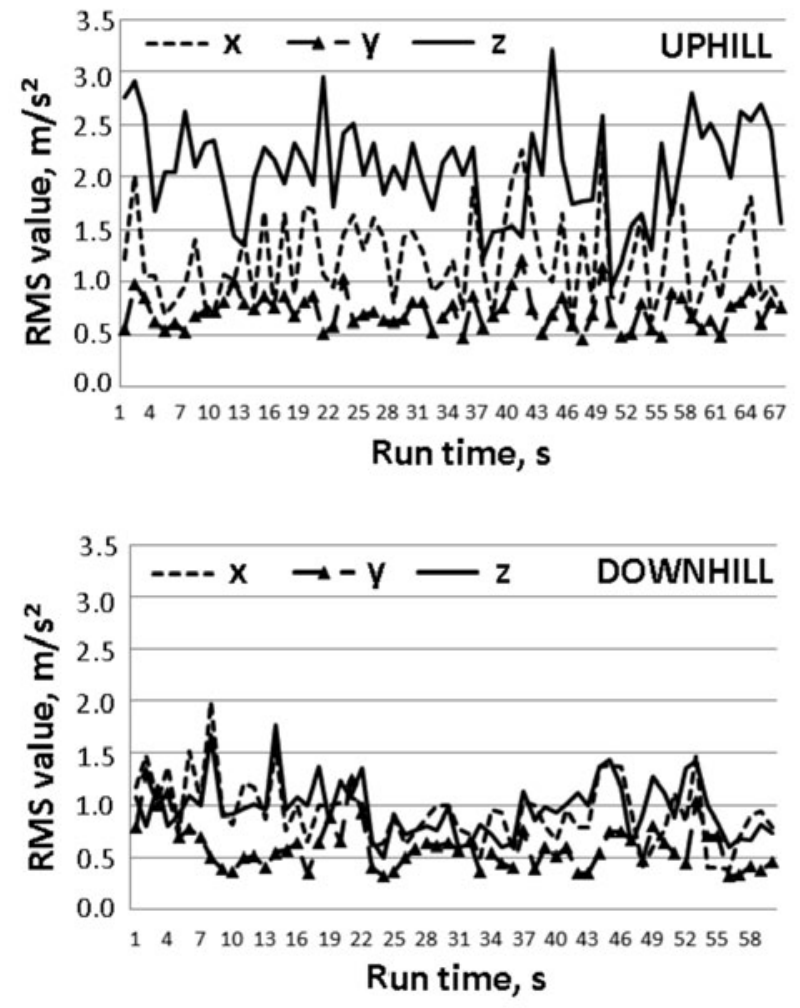

Figure 5. Time history of the vibration measurements on tractor $\mathrm{D}(1)$, equipped with 5 - roller track support, traveling uphill and downhill, with the maximum stiff setting of the mechanical suspension of the seat. RMS, root mean square.

Table 3. Overall root mean square $\left(a_{\text {wsum }}, \mathrm{m} / \mathrm{s}^{2}\right)$ values measured on conventional tracklaying tractors A, B and C. In a theoretical comparison with value stipulated in the Italian Decree No. 81/2008, all values exceeded the exposure limit except values in italics which exceeded the exposure action but not the exposure limit.

\begin{tabular}{lcccccc}
$\begin{array}{l}\text { Seat susp. } \\
\text { adjustment }\end{array}$ & A & Uphill & & \multicolumn{3}{c}{ Downhill } \\
Max. stiff & 2.00 & 1.90 & 1.83 & 1.69 & 1.12 & 1.85 \\
Correct & 1.20 & 1.07 & 1.92 & 1.06 & 0.88 & 1.83 \\
\hline Max. soft & 1.68 & 1.60 & 2.29 & 1.40 & 1.28 & 1.89 \\
\hline
\end{tabular}

Table 4. Overall root mean square $\left(a_{\text {wsum }}, \mathrm{m} / \mathrm{s}^{2}\right)$ values measured on $D(1)$ and $D(2)$ tractors with different track support rollers and type of seat suspension. In a theoretical comparison with values stipulated in the Italian Decree No. 81/2008, all values exceeded exposure limit except values in italics which exceeded the exposure action but not the exposure limit.

\begin{tabular}{|c|c|c|c|c|}
\hline \multirow{2}{*}{$\begin{array}{l}\text { Seat susp. } \\
\text { adjustment }\end{array}$} & \multicolumn{2}{|c|}{ Uphill } & \multicolumn{2}{|c|}{ Downhill } \\
\hline & $\begin{array}{l}5 \text { rollers } \\
\text { and } \\
\text { mech } \\
\text { susp. }\end{array}$ & $\begin{array}{c}6 \text { rollers } \\
\text { and } \\
\text { pneum. } \\
\text { susp. }\end{array}$ & $\begin{array}{c}5 \text { rollers } \\
\text { and } \\
\text { mech } \\
\text { susp. }\end{array}$ & $\begin{array}{c}6 \text { rollers } \\
\text { and } \\
\text { pneum. } \\
\text { susp. }\end{array}$ \\
\hline Max. stiff & 2.51 & 1.13 & 1.47 & 1.03 \\
\hline Correct & 1.81 & 1.14 & 1.50 & 0.85 \\
\hline Max. soft & 1.89 & 1.29 & 1.28 & 1.12 \\
\hline
\end{tabular}

arrangement, none of the single axes vibration levels measured exceeded $1.0 \mathrm{~m} / \mathrm{s}^{2}$.

Furthermore, the y (transversal) axis showed lower values when compared to the $\mathrm{x}$ axis (longitudinal); this is probably due to the coupling of the ripper hitched at the 3-point linkage, acting as a sort of spring able to stress the pitch movement of the tractor body.

Figure 5 shows one of the several possible comparisons between the uphill and downhill time history.

The $\mathrm{z}$ (vertical) axis highlighted the highest values moving uphill, while downhill the levels were generally lower, due to the smoother surface. Furthermore, the level peaks were clearly higher in the uphill path, confirming the unevenness of the ground.

Conventional tractors A, B and C (Table 3 ) showed very high overall RMS ( $\mathrm{a}_{\text {wsum }}$ ) levels both traveling uphill and downhill. In a theoretical comparison with values stipulated in the Italian Decree No. 81/2008, all values except one exceeded the exposure limit, even with the correct seat suspension adjustment. However, the values recorded on the correctly adjusted seats of tractors A and B were slightly higher than 1.0 $\mathrm{m} / \mathrm{s}^{2}$, while the increase in the maximum stiff and soft settings ranged from $60-100 \%$ traveling uphill and from 10-70\% traveling downhill. Performance on tractor $\mathrm{C}$ was always poor, and there was no significant difference even when the setting was changed.

The results obtained on the two versions of tractor D are particularly interesting (Table 4). The combination of the 6-roller tracks and the pneumatic suspension of $\mathrm{D}(2)$ always performed better than $\mathrm{D}(1)$ equipped with the 5-roller tracks and mechanical seat suspension.

The reduction in vibration is quite remarkable, ranging from 30-55\%. Again, with the best combination, both the uphill and downhill absolute values are very close to the exposure limit, and the difference among correct and incorrect seat suspension adjustments is markedly reduced. This represents a sort of added value, because a possible oversight when adjusting the setting does not necessarily translate into less comfortable driving conditions.

\section{Conclusions}

Drivers of agricultural tracklaying tractors run quite a high risk of discomfort from vibration. The average speed on a typical farm track is $7 \mathrm{~km} / \mathrm{h}$ and, at this speed, vibration levels always exceed $0.5 \mathrm{~m} / \mathrm{s}^{2}$, and very frequently even $1.0 \mathrm{~m} / \mathrm{s}^{2}$. Predictably, the situation will worsen at a higher traveling speed, up to $15 \mathrm{~km} / \mathrm{h}$, the maximum speed for tracklaying tractors. Operative factors related to the field itself could also lead to poor conditions of comfort, for example, due to the unevenness of the surface to be worked and the fact that the attached machinery will also contribute to the overall vibration level.

The type of seat suspension dramatically influences the level of comfort. Quite a good result was obtained with a seat equipped with a pneumatic rather than a mechanical suspension. The tests were repeated on two similar tractors each with a different track roller support and type of seat suspension. The 6-roller version performed better than the 5roller. This was probably due to the higher stability provided by a longer wheelbase and the increased surface of contact with the ground that were better able to absorb the unevenness of the soil. Unfortunately, it was not possible to evaluate separately the individual contribution of the number of rollers and the type of seat suspension.

As expected, the attachment of implements at the 3-point linkage increases the level of vibration, especially on the $\mathrm{x}$ (longitudinal) axis, probably because the pitch movement of the tractor is stressed.

A theoretical comparison was made with values stipulated by the Italian Decree No. 81/20008. In general, the overall RMS vibration $\left(a_{\text {wsum }}\right)$ levels recorded were always higher than the exposure action value $\left(0.5 \mathrm{~m} / \mathrm{s}^{2}\right)$, and also frequently exceeded the exposure limit (1.0 
$\mathrm{m} / \mathrm{s}^{2}$ ). In order to assure a suitable reduction in drivers risk, these results would require a reduction to be made in the total hours worked with respect to the traditional $8 \mathrm{~h} /$ day, sometimes with quite a radical cut of up to $2 \mathrm{~h} /$ day or even more. This is hardly realistic and, therefore, further measures to reduce vibration levels on tracklaying tractors are urgently required. Possible solutions could include the universal adoption of rubber tracks and/or the fitting of silent blocks on the cab floor and suspension devices on one or both axles.

\section{References}

Deprez K, Moshou D, Anthonis J, De Baerdemaeker J, Ramon H, 2005. Improvement of vibration comfort on agricultural vehicles by passive and semi-active cabin suspensions. Comput Electron Agric 49:431-440.

Hammes S, Meyer H, 2010. Entwicklung eines semi-aktiven Federungssystems fuer hydropnumatisch vollgefederte Traktoren. VDI-Berichte no. 2111, 31-41.

Nuccitelli G, Ragni L, 1993. Influenza della regolazione del sedile sulla trasmissione delle vibrazioni al conducente. Rivista di Ingegneria Agraria 3:143-150.

Pessina D, 1993. Valutazione delle vibrazioni sul sedile di guida di un trattore convenzionale equipaggiato con differenti pneumatici radiali. Proc. 5th National Congr. AIGR "Il ruolo dell'ingegneria per l'agricoltura del 2000", pp 429-440.

Scarlett AJ, Price JS, Stayner RM, 2007. Whole-body vibration: evaluation of emission and exposure levels arising from agricultural tracors. J. Terramechanics 44:65-73.

Servadio P, Marsili A, Belfiore N.P, 2007. Analysis of driving seat vibration in high forward speed tractors. Biosyst. Eng. 97, 171-180.

Solecki L, 2007. Preliminary recognition of whole body vibration risk in private farmers' working environment. AAEM 14:299-304.

Uys PE, Els PE, Thoresson M, 2007. Suspension settings for optimal ride comfort of off-road vehicles travelling on roads with different roughness and speeds. J. Terramechanics 44:163-175.

European Commission, 2002. Commission Decision of 6 July 2002 concerning minimum health and safety requirements regarding the exposure of workers to the risks arising from physical agents (vibration), 2002/44/EC. In: Official Journal, L 177, 06/07/2002, pp 13-20.

International Organization for Standardization, 1997. Mechanical vibration and shock - Evaluation of human exposure to whole-body vibration. IS0 standard 2631-1. Vol. Part. 1: General requirements.

Italian Directive, 2008. Application of the Italian Directive No. 81/2008. Attuazione dell'articolo 1 della legge 3 agosto 2007, No. 123, in materia di tutela della salute e della sicurezza nei luoghi di lavoro. In: Gazzetta Ufficiale No. 101, 30/4/2008, suppl. ord. No. 108. 